\title{
Editorial changes - Advances in Water Resources
}

\section{Prof. Cass T. Miller (University of North Carolina, Chapel Hill) stepped down as Editor on 30 June 2015}

Prof. Miller's longevity of service as Editor is remarkable - he started this role in August 1997. During his nearly 18 years as Editor, he provided unstinting energy, attention to detail, and commitment to the water resources community. A hallmark of his stewardship of the journal is that he "led from the front". He undertook not only to sustain a suitable venue for high quality research, but also to foster special issues, especially in emerging research topics. Prof. Miller ensured that at all times the journal's core focus of fundamental water resources science was not diluted. Indeed, a major legacy of Prof. Miller's vision is that the journal is a destination of choice for such contributions.

Besides his "big picture" leadership, Prof. Miller was keenly aware of the expectations of the researcher base served by the journal. He fulfilled such expectations by close attention to the many unsung details that are inherent in the operation of a journal, particularly efficient handling of manuscripts, selection of insightful reviewers and, importantly, maintaining an active Editorial Board of leading researchers.

Prof. Miller leaves the journal in robust health. Undoubtedly, his influence will be felt for many years to come. We wish to maintain his high standards, collegiality and spirit of service to the community served by the journal. On behalf of Advances in Water Resources, his fellow editors thank Prof. Miller for his dedicated service to the journal and his visionary, collegial, and charismatic leadership of the editorial team.

With the departure of Prof. Miller, we welcome as Editor Prof. Graham Sander (Loughborough University). Prof. Sander brings significant editorial experience along with expertise in several areas of interest to the journal, including vadose zone and multiphase flow, analytical and numerical methods, overland and river flow, and soil erosion.

The journal has also expanded its editor team with several Associate Editors. These AEs bring significant expertise in a variety of domains within the broad spectrum of water resources, and will play an active part in the future growth and standing of the journal.

\section{Associate Editors}

Carlo De Michele (Politecnico di Milano) statistical hydrology, frequency analysis by copulas, water engineering, ecohydrology.

Vittorio Di Federico (Università di Bologna) subsurface hydrology, geophysical fluid dynamics, uncertainty-based analysis, groundwater quality, urban hydraulics.

Rui Ferreira (Instituto Superior Técnico, Lisbon) fluid mechanics, mechanics of sediment transport, fluvial hydraulics, environmental hydraulics, computational hydraulics.

Balaji Rajagopalan (University of Colorado, Boulder) hydroclimatology, low-frequency climate variability, stochastic hydrology, statistical climate modelling.

Matthew Reidenbach (University of Virginia) environmental fluid dynamics, plant fluid interactions, coastal hydrodynamics.

Gabriele Villarini (University of Iowa) hydroclimatology, extreme events, climate predictions and projections, forecasting, remote sensing of rainfall, economic impacts of natural hazards.

Adrian Werner (Flinders University) groundwater hydrology, coastal hydrogeology, water resources management, surface watergroundwater interaction.

Brian Wood (Oregon State University, Corvallis) mass, momentum, and energy transport in natural and engineered multiscale systems, fundamentals of reactive transport, thermodynamics.

Hund-Der Yeh (National Chiao Tung University) groundwater hydrology, subsurface transport processes, statistical and stochastic hydrology.

D.A. Barry P. D'Odorico

A. Rinaldo

E-mail address: andrew.barry@epfl.ch (D.A. Barry)

Received 24 July 2015 